\title{
Birth preparedness and complication readiness among pregnant women attending antenatal care at the Faculty of Medicine Vajira Hospital, Thailand
}

This article was published in the following Dove Press journal: International Journal of Women's Health

\author{
Nath Kiataphiwasu \\ Kasemsis Kaewkiattikun \\ Department of Obstetrics \& \\ Gynecology, Faculty of Medicine Vajira \\ Hospital, Navamindradhiraj University, \\ Bangkok, Thailand
}

Background: Maternal and neonatal mortality is a major health problem in developing countries. Birth preparedness and complication readiness (BPCR) is a strategy to encourage pregnant women to make prompt decisions to seek care from skilled birth attendants. Reports of good BPCR vary depending on study setting and population. Most studies of BPCR have been conducted in developing countries, BPCR status and associated factors in Thailand are currently unknown.

Objective: To discover the proportion of good BPCR (at least four BPCR indicators), associated factors and predictive factors for good BPCR in pregnant women attending antenatal clinic.

Materials and methods: This cross-sectional study was conducted among pregnant women attending the antenatal clinic at the Department of Obstetrics and Gynecology, Faculty of Medicine Vajira Hospital, Thailand, from May 1 to December 31, 2017. The participants were interviewed using the BPCR index developed by the John Hopkins Program for International Education in Gynecology and Obstetrics.

Results: Of a total 672 pregnant women, the proportion of good BPCR was $78.6 \%$. The association between baseline characteristics with BPCR status revealed that the good BPCR group was significantly associated with adult pregnancy, married, high education, being employed, high income, extended family, multiparity, first antenatal visit $\leq 12$ weeks and average distance to the hospital $>2$ hours. Results from multiple logistic regression found that significant predictive factors for good BPCR were a diploma or a bachelor's degree $\left(\mathrm{OR}_{\text {adj }} 2.09,95 \% \mathrm{CI}\right.$ 1.19-3.69, $P=0.010)$, income more than 10,000 baht $\left(\mathrm{OR}_{\text {adj }} 2.63,95 \% \mathrm{CI} 1.37-5.05, P=0.004\right)$, extended family $\left(\mathrm{OR}_{\text {adj }} 2.32,95 \% \mathrm{CI} 1.41-3.82, P=0.001\right)$ and multiparity $\left(\mathrm{OR}_{\text {adj }} 1.56,95 \% \mathrm{CI}\right.$ 1.01-2.42, $P=0.047)$.

Conclusion: This study demonstrated that the proportion of good BPCR among pregnant women attending antenatal care was high. Associated factors of good BPCR were adult pregnancy, married status, high education, employed, high income, extended family, multiparity, first antenatal visit at $\leq 12$ weeks and long-distance transportation. Predictive factors for good BPCR were high education, high income, multiparity and extended family.

Keywords: birth, birth preparedness, complication readiness, BPCR, maternal mortality, Thailand

\section{Introduction}

Pregnancy is a very sensitive period in which unexpected life-threatening complications may arise at any period, from conception to the postpartum period. Maternal and neonatal mortality is an ongoing major public health problem in developing countries. In 2015, the WHO estimates that $\sim 830$ women die every day from preventable causes related to pregnancy and childbirth, and $99 \%$ of all maternal deaths occur in developing countries. ${ }^{1,2}$
Correspondence: Kasemsis Kaewkiattikun Department of Obstetrics \& Gynecology, Faculty of Medicine Vajira Hospital, Navamindradhiraj University, Bangkok 10300, Thailand Tel +6689536660 l Email kasem38@hotmail.com 
Most maternal death is a consequence of complications during and following pregnancy and childbirth, most of which are preventable or treatable when births are assisted by skilled birth attendants. ${ }^{3}$ Although a safe motherhood program is successful in reducing maternal mortality, it does not mean high utilization of maternal health services. The problem may be due to the delays in seeking, reaching and receiving adequate care. ${ }^{4}$ One effective strategy to prevent maternal mortality is birth preparedness and complication readiness (BPCR), which will encourage pregnant women to make prompt decisions to seek care from skilled birth attendants.

BPCR is a strategy to promote the timely use of skilled maternal and neonatal care, especially during childbirth. With this aim in mind, in 2001, The Maternal and Neonatal Health Program of John Hopkins Program for International Education in Gynecology and Obstetrics (JHPIEGO) developed the BPCR matrix, which is a standard set of indicators that could be used across countries. BPCR matrix explains the roles of policymakers, facility managers, health care providers, communities, families and women in ensuring that women and newborns receive timely skilled maternal and neonatal care based on the theory that preparing for childbirth and being ready for complications reduce delays in seeking and obtaining appropriate care. ${ }^{5}$ A report from Ethiopia showed that BPCR had a significant effect on skilled care use. ${ }^{6}$ Moreover, there is clear evidence from a meta-analysis of 14 randomized studies showing that BPCR interventions, with adequate population coverage, are effective in reducing maternal and neonatal mortality in low-resources setting. ${ }^{7}$

However, reports of good BPCR vary from $15 \%$ to $70 \%,{ }^{8,9}$ depending on study setting and population. Most studies of BPCR were conducted in developing countries, such as Ethiopia, India, Nigeria, Tanzania and Ghana. Little is known about the BPCR status and associated factors in Thailand. Moreover, the majority of earlier published papers were conducted in rural or peri-urban areas. There are few studies in urban settings where available health care facilities, sociodemographics and cultural conditions are different. This study, therefore, aimed to assess the BPCR status and factors associated with BPCR among pregnant women attending antenatal care (ANC) at Faculty of Medicine Vajira Hospital, Bangkok. Additionally, results of this study will contribute to provide valuable information for service providers, policy makers, development partners, and programmers to design effective BPCR programs and interventions in an attempt to reduce maternal and neonatal mortality rates in Thailand. Furthermore, it is hoped that the results also serve as baseline information for further study.

\section{Materials and methods}

A cross-sectional study was conducted among antenatal pregnant women at the Department of Obstetrics and Gynecology, Faculty of Medicine Vajira Hospital, Navamindradhiraj University, Bangkok, Thailand, from May 1 to December 31, 2017. Approval for the study was obtained from the Research Ethics Board at Faculty of Medicine Vajira Hospital, and all the study subjects gave written informed consent during antenatal period.

The studied population consisted of all antenatal pregnant women who planned to give birth at Department of Obstetrics \& Gynecology, Faculty of Medicine Vajira Hospital. Inclusion criteria were mothers of Thai nationality who could communicate in Thai, low-risk pregnancy and gestational age of 20 weeks or more. Exclusion criteria were having maternal and fetal complications at date of interview.

Sample size was calculated based on previous studies in India; they found that $35.85 \%$ of pregnant women had good BPCR. ${ }^{10}$ The powers of $80 \%$ and a level of confidence of $95 \%$ were applied to determine the difference between groups. Adding 10\% for incomplete data, a total of 672 participants were included in this study by computerized simple random sampling technique. Then a research assistant would interview the pregnant woman who matched the random number.

All participants who were $\geq 18$ years old were informed of the study processes by a research assistant at antenatal clinic and gave written informed consent. For those participants, who were under the legal age of consent (under 18 years old), the participants and their parents or legal guardians were informed of the study processes at antenatal clinic by a research assistant. After understanding all processes, their parents or legal guardians provided informed consent on their behalf.

The participants were interviewed using a structured questionnaire which included socio-demographic profile, parity, gestational age at initial antenatal care, place of residence and average distance from the hospital. The questionnaire for individual level BPCR index was developed from the JHPIEGO and includes knowledge of danger signs during pregnancy, labor, postpartum and, in newborns, plan to attend at least four antenatal care visits with a skilled provider; attend first ANC visit with a skilled provider during first trimester; plan to give birth with a skilled provider; plan to save money for a childbirth and plan to identify a mode of transport to the place of delivery. ${ }^{11}$ The participants who fulfilled at least four BPCR practices were considered as "well prepared" and the rest of them were "poorly prepared". ${ }^{10,12}$ 
Eligible and consenting women were interviewed by a welltrained research assistant.

The primary outcome of this study was the proportion of good BPCR in pregnant women attending ANC clinic. The secondary outcomes were risk factors and predicting factors of good BPCR. The data were analyzed by statistician using SPSS version 22 (IBM Corp., Armonk, NY, USA). ${ }^{13}$ Chisquared test was used for categorical data analysis. Univariate and multivariate analyses were further entered into logistic regression analysis to determine independent predictors of good BPCR and presented as odds ratio and 95\% CI. $P$-value of less than 0.05 was considered statistically significant.

\section{Results}

A total of 672 pregnant women were eligible for analysis. Of all the participants, $528(78.6 \%)$ pregnant women had good BPCR by fulfilling at least four BPCR indicators and the remaining 144 (21.4\%) showed poor BPCR. Of the six indicators of BPCR, $74.7 \%$ knew at least eight key danger signs during pregnancy, labor, postpartum and, in the newborn,
$70.4 \%$ planned to attend at least four antenatal care visits with a skilled provider, $76.0 \%$ attended first antenatal care session with a skilled provider during first trimester, $86.8 \%$ planned to give birth with a skilled provider, $50.7 \%$ planned to save money for a childbirth and $85.4 \%$ planned to identify a mode of transport to the place of delivery. Therefore, the most mentioned BPCR indicator was planning to give birth with a skilled provider, and the least mentioned BPCR indicator was planning to save money for the childbirth (Table 1).

The least known obstetric danger sign of all phases of pregnancy was danger signs during labor (47.0\%). The most mentioned danger sign of obstetric complications was severe vaginal bleeding $(87.5 \%, 83.5 \%$ and $87.5 \%$ during pregnancy, labor and postpartum, respectively). The least mentioned danger sign was retained placenta (43.5\%). Overall, the respondents were able to mention more newborn danger signs than obstetric danger signs. However, the least known danger sign in the newborns was lethargy/unconscious.

Table 2 shows baseline characteristics of antenatal women. The demographic characteristics of all 672 antenatal women

Table I BPCR among antenatal women

\begin{tabular}{|c|c|c|}
\hline Variables* & Number & Percentage \\
\hline \multicolumn{3}{|l|}{ BPCR (at least four indicators) } \\
\hline Good BPCR & 528 & 78.6 \\
\hline Poor BPCR & 144 & 21.4 \\
\hline \multicolumn{3}{|l|}{ BPCR indicators } \\
\hline I. Knew at least 8 key danger signs during pregnancy, labor, postpartum and in the newborn & 502 & 74.7 \\
\hline - Knew about danger signs during pregnancy (all 3 signs) & 429 & 63.8 \\
\hline Severe vaginal bleeding & 588 & 87.5 \\
\hline Swollen hands/face & 501 & 74.6 \\
\hline Blurred vision & 463 & 68.9 \\
\hline - Knew about danger signs during labor (all 4 signs) & 316 & 47.0 \\
\hline Severe vaginal bleeding & 561 & 83.5 \\
\hline Prolonged labor ( $>12$ hours) & 420 & 62.5 \\
\hline Convulsion & 317 & 47.2 \\
\hline Retained placenta & 292 & 43.5 \\
\hline - Knew about danger signs during postpartum (all 3 signs) & 320 & 47.6 \\
\hline Severe vaginal bleeding & 590 & 87.8 \\
\hline Foul smelling vaginal discharge & 494 & 73.5 \\
\hline Prolonged fever ( $>24$ hours) & 457 & 68.0 \\
\hline - Knew about danger signs in the newborn (all 4 signs) & 490 & 72.9 \\
\hline Convulsion/spasms/rigidity & 570 & 84.8 \\
\hline Difficult/fast breathing & 572 & 85.1 \\
\hline Very small baby & 513 & 76.3 \\
\hline Lethargy/unconscious & 501 & 74.6 \\
\hline 2. Plan to attend at least 4 antenatal care visits with a skilled provider & 473 & 70.4 \\
\hline 3. Attending Ist antenatal care with a skilled provider during first trimester & 511 & 76.0 \\
\hline 4. Plan to give birth with a skilled provider & 583 & 86.8 \\
\hline 5. Plan to save money for a childbirth & 341 & 50.7 \\
\hline 6. Plan to identify a mode of transport to place of childbirth & 574 & 85.4 \\
\hline
\end{tabular}

Note: *multiple responses.

Abbreviaiton: BPCR, birth preparedness and complication readiness. 
Table 2 Demographic Characteristics of women attending ANC clinics and association with BPCR

\begin{tabular}{|c|c|c|c|c|}
\hline \multirow[t]{2}{*}{ Characteristic } & \multirow{2}{*}{$\begin{array}{c}\text { Total } \\
(n=672)\end{array}$} & \multicolumn{2}{|c|}{ BPCR status } & \multirow[t]{2}{*}{$P$-value } \\
\hline & & Good BPCR $(n=528)$ & Poor BPCR $(n=144)$ & \\
\hline \multicolumn{5}{|l|}{ Age (years) } \\
\hline $10-19$ & $54(8.0)$ & $39(72.2)$ & $15(27.8)$ & 0.038 \\
\hline $20-29$ & $358(53.3)$ & $270(75.4)$ & $88(24.6)$ & \\
\hline$\geq 30$ & $260(38.7)$ & $219(84.2)$ & $4 I(15.8)$ & \\
\hline \multicolumn{5}{|l|}{ Body mass index } \\
\hline Normal & $159(23.7)$ & $126(79.2)$ & $33(20.8)$ & $0.58 \mathrm{I}$ \\
\hline Over weight & $125(18.6)$ & $102(81.6)$ & $23(18.4)$ & \\
\hline Obese & $388(57.7)$ & $300(77.3)$ & $88(22.7)$ & \\
\hline \multicolumn{5}{|l|}{ Marital Status } \\
\hline Single & $115(17.1)$ & $89(77.4)$ & $26(22.6)$ & 0.006 \\
\hline Married & $525(78.1)$ & $42 \mathrm{I}(80.2)$ & $104(19.8)$ & \\
\hline Divorced & $32(4.8)$ & $18(56.3)$ & $14(43.8)$ & \\
\hline \multicolumn{5}{|l|}{ Educational status } \\
\hline Elementary and secondary school & $423(62.9)$ & $307(72.6)$ & $116(27.4)$ & $<0.001$ \\
\hline Diploma and bachelor's degree & $249(37.1)$ & $221(88.8)$ & $28(11.2)$ & \\
\hline \multicolumn{5}{|l|}{ Occupation } \\
\hline Unemployed & $222(33.0)$ & I59 (7I.6) & $63(28.4)$ & 0.005 \\
\hline Office employee & $226(33.7)$ & $181(80.1)$ & $45(19.9)$ & \\
\hline Government officer & $224(33.3)$ & $188(83.9)$ & $36(16.1)$ & \\
\hline \multicolumn{5}{|l|}{ Income (THB) } \\
\hline$<10,000$ & $220(32.7)$ & $145(65.9)$ & $75(34.1)$ & $<0.001$ \\
\hline$\geq 10,000$ & $452(67.3)$ & $383(84.7)$ & $69(15.3)$ & \\
\hline \multicolumn{5}{|l|}{ Type of family } \\
\hline Nuclear family & $474(70.5)$ & $357(75.3)$ & 117 (24.7) & 0.001 \\
\hline Extended family & $198(29.5)$ & |7| (86.4) & $27(13.6)$ & \\
\hline \multicolumn{5}{|l|}{ Place of residence } \\
\hline Rural & $244(36.3)$ & $188(77.0)$ & $56(23.0)$ & 0.468 \\
\hline Bangkok metropolitan region & $428(63.7)$ & $340(79.4)$ & $88(20.6)$ & \\
\hline \multicolumn{5}{|l|}{ Average distance from the hospital } \\
\hline$\leq 2$ hours & $43(6.4)$ & $27(62.8)$ & $16(37.2)$ & 0.009 \\
\hline$>2$ hours & $629(93.6)$ & $50 \mathrm{I}(79.7)$ & $128(20.3)$ & \\
\hline \multicolumn{5}{|l|}{ Educational status of husband } \\
\hline Elementary or secondary school & $473(70.4)$ & $353(74.6)$ & $120(25.4)$ & $<0.001$ \\
\hline Diploma or bachelor's degree & $199(29.6)$ & $175(87.9)$ & $24(12.1)$ & \\
\hline \multicolumn{5}{|l|}{ Husband's occupation } \\
\hline Unemployed & $56(8.3)$ & $38(67.9)$ & $18(32.1)$ & 0.003 \\
\hline Office employee & $470(69.9)$ & $362(77.0)$ & $108(23.0)$ & \\
\hline Government officer & $146(2 \mid .8)$ & $128(87.7)$ & $18(12.3)$ & \\
\hline \multicolumn{5}{|l|}{ Parity (P) } \\
\hline Primiparity & $321(47.8)$ & $24 I(75 . I)$ & $80(24.9)$ & 0.035 \\
\hline Multiparity & $351(52.2)$ & $287(81.8)$ & $64(18.2)$ & \\
\hline \multicolumn{5}{|l|}{ Gestational Age at Ist ANC } \\
\hline$>12$ weeks & $361(53.7)$ & $269(74.5)$ & $92(25.5)$ & 0.006 \\
\hline$\leq 12$ weeks & $311(46.3)$ & $259(83.3)$ & $52(16.7)$ & \\
\hline \multicolumn{5}{|l|}{ Number of ANC } \\
\hline$<4$ & $130(19.3)$ & $98(75.4)$ & $32(24.6)$ & 0.324 \\
\hline$\geq 4$ & $542(80.7)$ & $430(79.3)$ & $112(20.7)$ & \\
\hline
\end{tabular}

Note: Data are presented as number (\%).

Abbreviations: ANC, antenatal care; BPCR, birth preparedness and complication readiness; THB, Thai Baht.

revealed that the majority were 20-29 years old (53.3\%), obese $(57.7 \%)$, married $(78.1 \%)$, had an elementary and secondary school education (62.9\%), had income $\geq 10,000$ THB (67.3\%), had a nuclear family (70.5\%), lived in Bangkok (63.7), average distance to hospital $>2$ hours
(93.6\%), their husbands had an elementary and secondary school education (70.4\%) and worked in offices (69.9\%). The obstetric characteristics showed that the majority were multipara (52.2\%), had gestational age at first ANC $>12$ weeks (53.7\%), number of ANC $\geq 4(80.7 \%)$. 
The association between baseline characteristics with BPCR status, good BPCR $(n=528)$ and poor BPCR $(n=144)$ is shown in Table 2. Pregnant women with good BPCR were significantly older adults $(P=0.038)$, mostly married ( $P=0.006$ ), with more educated to diploma and bachelor level than elementary and secondary school $(P<0.001)$, more were government officers than office employees and unemployed $(P=0.005)$, had higher incomes than low income $(P<0.001)$, had more extended families than nuclear families $(P=0.001)$, lived a greater average distance from the hospital $(P=0.009)$, their husbands had more diploma and bachelorlevel education than elementary and secondary school $(P<0.001)$ and more were government officers than office employees and unemployed $(P=0.003)$. Finally, the mothers had more multiparity than primiparity $(P=0.035)$ and more first antenatal visits at $\leq 12$ weeks than at $>12$ weeks $(P=0.006)$.

To analyze factors predicting good BPCR, univariate logistic regression analysis found that age, marital status, education, occupation, income, family type, parity, gestational age at first ANC, average distance to the hospital, husband's education and husband's occupation were significant factors $(P<0.10)$. After adjusting OR estimated by multiple logistic regression adjusting for age, marital status, education, occupation, income, family type, parity, gestational age at first ANC, average distance to hospital, husband's education and husband's occupation were analyzed. The adjusted OR estimated by multivariate logistic regression analysis revealed that the significant factors predicting good BPCR were pregnant women who had a diploma or a bachelor's degree $\left(\mathrm{OR}_{\text {adj }} 2.09,95 \% \mathrm{CI} 1.19-3.69, P=0.010\right)$, had income over 10,000 baht $\left(\mathrm{OR}_{\text {adj }} 2.63,95 \%\right.$ CI 1.37-5.05, $P=0.004)$, had extended family $\left(\mathrm{OR}_{\text {adj }} 2.32,95 \% \mathrm{CI} 1.41-\right.$ $3.82, P=0.001)$ and were multiparity $\left(\mathrm{OR}_{\text {adj }} 1.56,95 \% \mathrm{CI}\right.$ $1.01-2.42, P=0.047$ ) (Table 3).

\section{Discussion}

This cross-sectional study has identified the proportions and predicting factors of good BPCR. Results demonstrated that the proportion of pregnant women who had good BPCR was $78.6 \%$. This finding is consistent with the result of one study in Kenya, in which women participated in an active Community Health Strategy program offering free maternal and child health services. They found that $70.5 \%$ of women attending antenatal care clinic were prepared for birth, while $90.6 \%$ reported readiness for complications. ${ }^{9}$ Moreover, a similar finding was reported from India, where a study was conducted in an urban tertiary hospital. ${ }^{14}$

Nevertheless, the findings of this study revealed greater birth preparedness than prior reports, which mostly studied lower-middle income countries. The proportion of wellprepared pregnant women was $30 \%-57 \%$ in India, ${ }^{15-17} 19 \%$ in Ghana, ${ }^{18} 48.8 \%$ in Nigeria, ${ }^{19} 17 \%-54 \%$ in Ethiopia ${ }^{21,21}$ and $58 \%$ in Tanzania. ${ }^{22}$ There has not yet been any report of BPCR from developed countries. The higher proportion of good BPCR in this study may be due to its urban setting and tertiary care hospital where the population have better awareness and access to health information through general health education and different media, ${ }^{21}$ despite there being no BPCR intervention in our institute. Furthermore, this study was based in a tertiary-level health care facility in an inner urban area, which could account for mothers' higher levels of awareness of birth preparation and planning. Another limitation is that we have little information about home births and the level of birth preparedness and complications as our study focused on the population of mothers who access our hospital services. Since BPCR intervention can increase preparation for birth and complications, ${ }^{23}$ implementation of a BPCR program as an essential part of antenatal education is recommended to increase the BPCR rate above the existing result.

When considering birth preparedness indicators, the most mentioned indicator was planning to give birth with a skilled provider $(86.8 \%)$, followed by planning to identify a mode of transport to the place of childbirth (85.4\%). These findings indicate that the majority of pregnant women gave priority to birthplace access and safe delivery. Similar findings were reported by a study in India in which the majority of the participants identified a skilled provider for delivery $(98.14 \%)$ and had made arrangements of vehicle for transportation $(72.25 \%)$, despite being conducted in a rural area with low BPCR index score. ${ }^{17}$ Moreover, this study also found that the least mentioned indicator was planning to save money for a childbirth (50.7\%). This low level of money saving for childbirth suggests health care personnel should counsel about all expenses and financial planning during ANC sessions.

Of all BPCR indexes, the most important index is knowing of the danger signs of obstetric and newborn complications, because it indicates readiness for pregnancy complications and is an essential first step in their recognition along with taking appropriate and timely action to access hospital for emergency obstetric and newborn care. ${ }^{24}$ Moreover, there is clear evidence that knowledge of danger signs is associated with good BPCR. Reports from Uganda and Ethiopia showed that women who were knowledgeable of danger signs were 2-4 times more likely to have greater BPCR as compared with those who were not knowledgeable. ${ }^{20,21,25,26}$ This study revealed that $74.7 \%$ of pregnant women knew the danger signs, which is higher than previous studies. Although this 
Table 3 Univariate and multiple logistic regression analysis of factors associated with good BPCR

\begin{tabular}{|c|c|c|c|c|c|c|}
\hline \multirow[t]{2}{*}{ Factors } & \multicolumn{3}{|c|}{ Univariate analysis } & \multicolumn{3}{|c|}{ Multivariate analysis } \\
\hline & OR' $^{\prime}$ & $95 \% \mathrm{Cl}$ & $P$-value & $\mathbf{O R}_{\mathrm{adj}}^{2}$ & $95 \% \mathrm{Cl}$ & $P$-value \\
\hline \multicolumn{7}{|l|}{ Age (years) } \\
\hline $10-19$ & 1.00 & Reference & & 1.00 & Reference & \\
\hline $20-29$ & 1.18 & $(0.62-2.24)$ & 0.613 & 0.52 & $(0.25-1.06)$ & 0.070 \\
\hline $30-39$ & 2.02 & $(1.01-4.03)$ & 0.047 & 0.56 & $(0.25-1.26)$ & 0.159 \\
\hline$\geq 40$ & 2.40 & $(0.72-8.08)$ & 0.156 & 0.98 & $(0.26-3.66)$ & 0.977 \\
\hline \multicolumn{7}{|l|}{ Marital Status } \\
\hline Single & 1.00 & Reference & & 1.00 & Reference & \\
\hline Married & 1.18 & $(0.73-1.92)$ & 0.500 & 0.93 & $(0.55-1.58)$ & 0.783 \\
\hline Divorced & 0.38 & $(0.17-0.86)$ & 0.020 & 0.46 & $(0.19-1.11)$ & 0.084 \\
\hline \multicolumn{7}{|l|}{ Education } \\
\hline Elementary or high school & 1.00 & Reference & & 1.00 & Reference & \\
\hline Diploma and bachelor's degree & 2.98 & $(1.91-4.67)$ & $<0.001$ & 2.09 & $(1.19-3.69)$ & 0.010 \\
\hline \multicolumn{7}{|l|}{ Occupation } \\
\hline Unemployed & 1.00 & Reference & & 1.00 & Reference & \\
\hline Office employee & 1.59 & $(1.03-2.47)$ & 0.037 & 1.61 & $(0.98-2.65)$ & 0.062 \\
\hline Government officer & 2.07 & $(1.31-3.28)$ & 0.002 & 1.15 & $(0.65-2.01)$ & 0.638 \\
\hline \multicolumn{7}{|l|}{ Family income (THB) } \\
\hline$<10,000$ THB & 1.00 & Reference & & 1.00 & Reference & \\
\hline$\geq 10,000 \mathrm{THB}$ & 4.63 & $(2.73-7.87)$ & $<0.001$ & 2.63 & $(1.37-5.05)$ & 0.004 \\
\hline \multicolumn{7}{|l|}{ Family type } \\
\hline Nuclear family & 1.00 & Reference & & 1.00 & Reference & \\
\hline Extended family & 2.08 & $(1.32-3.28)$ & 0.002 & 2.32 & $(\mathrm{I} .4 \mathrm{I}-3.82)$ & 0.001 \\
\hline \multicolumn{7}{|l|}{ Average distance from the hospital } \\
\hline$\leq 2$ hours & 1.00 & Reference & & 1.00 & Reference & \\
\hline$>2$ hours & 2.32 & $(1.21-4.44)$ & 0.011 & 1.67 & $(0.82-3.4 I)$ & 0.159 \\
\hline \multicolumn{7}{|l|}{ Husband's education } \\
\hline Elementary or secondary school & 1.00 & Reference & & 1.00 & Reference & \\
\hline Diploma or bachelor's degree & 2.48 & $(1.54-3.98)$ & $<0.001$ & 1.64 & $(0.92-2.92)$ & 0.094 \\
\hline \multicolumn{7}{|l|}{ Husband's occupation } \\
\hline Student, unemployed & 1.00 & Reference & & 1.00 & Reference & \\
\hline Office staff & 1.59 & $(0.87-2.90)$ & 0.131 & 1.32 & $(0.65-2.66)$ & 0.439 \\
\hline Government official and others & 3.37 & $(1.60-7.11)$ & 0.001 & 1.27 & $(0.54-3.00)$ & 0.583 \\
\hline \multicolumn{7}{|l|}{ Parity $(\mathrm{P})$} \\
\hline Primiparity & 1.00 & Reference & & 1.00 & Reference & \\
\hline Multiparity & 1.49 & $(1.03-2.16)$ & 0.035 & 1.56 & $(\mathrm{I} .0 \mathrm{I}-2.42)$ & 0.047 \\
\hline \multicolumn{7}{|l|}{ Gestational age at Ist ANC } \\
\hline$>12$ weeks & 1.00 & Reference & & 1.00 & Reference & \\
\hline$<12$ weeks & 1.70 & $(1.16-2.49)$ & 0.006 & 1.46 & $(0.96-2.21)$ & 0.075 \\
\hline
\end{tabular}

Note: OR, odds ratio; ORadj, adjusted odds ratio; $\mathrm{Cl}$, confidence interval. 'Crude OR estimated by binary logistic regression, ${ }^{2} \mathrm{OR}$ adi estimated by multiple logistic regression.

Abbreviations: ANC, antenatal care; BPCR, birth preparedness and complication readiness; THB, Thai Baht.

figure is high, it does not guarantee that an individual will recognize it in practice, because danger signs are measuring spontaneous knowledge without fully measuring an individual's ability to recognize problems and grasp the severity of danger signs. ${ }^{11}$ A study from South West Ethiopia showed low pregnancy danger sign awareness despite having heard about BPCR before. ${ }^{27}$ Delays in seeking, reaching and obtaining care may be due to many factors, such as understanding importance of each danger sign, decision to seek care, accessibility to facilities, financial status, family and community support, socioeconomic and cultural factors and receiving adequate and proper treatment. ${ }^{11}$ To increase BPCR, health care personnel should not only routinely provide knowledge of danger signs but also explain severity and progression of danger symptoms and signs, together with initial care before going to hospital.

Considering each aspect of danger sign knowledge, this study found that less than $50 \%$ of participants were knowledgeable in danger signs during labor and the postpartum period, which needs improvement to increase awareness of danger signs. The most commonly mentioned danger sign across all the three phases in this study was vaginal bleeding, which was comparable with previous studies. ${ }^{9,28,29}$ This can be explained by the fact that vaginal bleeding is a visible 
symptom that women feel is harmful to the fetus, which makes them realize that it is a danger sign of pregnancy. However, it is also necessary to educate pregnant women about other symptoms which are also dangerous to mother and baby.

This study also found that well-prepared women were significantly older, more likely to be married, had high incomes, more educated spouses, greater spouse employment, more multiparity, earlier ANC visits and more extended family than less prepared women. These characteristics are likely to lead to better pregnancy preparedness and readiness for pregnancy complications. This highlights the need to encourage pregnant women to attend early ANC for good BPCR. Moreover, health care personnel should also provide BPCR intervention to pregnant women who are at risk of poor BPCR, such as adolescents, primipara, the poorly educated, unemployed or those of low socioeconomic status.

After adjusting for confounding effects using multiple logistic regression analysis, this study found that women with good BPCR women had 2.09 times higher education, 2.63 times more income, 1.56 times more multiparity and 2.32 times more extended family than women with poor BPCR women. Thus, BPCR intervention in this group will have a greater chance of good BPCR. This finding is similar to an earlier report from India, which was conducted in an urban setting and tertiary care hospital, like this study. They found that the predictors of BPCR were multiparity, educational status and ANC at first trimester. ${ }^{14}$

The results of this study have implications for institutes to implement BPCR programs with adequate population coverage. Moreover, health professionals should provide BPCR counseling to all pregnant women during the antenatal period. This approach may be generalizable to pre-conceptional women to prevent maternal and neonatal mortality. Additionally, postpartum mothers probably benefit from BPCR counseling for further pregnancy.

\section{Strengths and limitations}

The strengths of this study were large sample size, the questionnaire of BPCR index was developed from JHPIEGO and the participants were interviewed by a well-trained research assistant. However, this study had many limitations, it was a cross-sectional study, hence the relationship between variables could not be proven. The answers were self-reported with no means of verification and thus subject to bias. Moreover, participants were interviewed while currently pregnant, rather than after completing their pregnancies; they may not yet have had the opportunity or need to decide on BPCR. Another limitation of this study includes factors that might affect BPCR status, such as attitudes and beliefs about birth preparedness, decision-making power, male partner influence, socioeconomic status of family, accessibility to health care services and reasons for seeking health care service that were not evaluated. Further research would study BPCR status comparing adult and adolescent pregnancy. Other research could study the effect of BPCR implementation on BPCR status. Moreover, suggestions for future research should be extended to the study of family and community roles in BPCR.

\section{Conclusion}

Although BPCR in this study was high, implementation of a BPCR program as a part of antenatal education is essential to increase BPCR awareness. Older, married pregnant women with high education, high economic status, multiparity, early ANC and extended family were more likely to have good BPCR. This study recommends health care personnel to encourage pregnant women to attend early ANC. Predictive factors for good BPCR were high education, high income, multiparity and extended family. BPCR intervention in this group during ANC period is likely to increase BPCR level.

\section{Acknowledgments}

The authors would like to thank all participants in the study and all staff of the data collection team. The authors also express their gratitude and thanks to Mr Jason Cullen for proof reading the earlier drafts of the manuscript. Finally, this study was made possible through funding and support from the Faculty of Medicine, Vajira Hospital, Navamindradhiraj University. The funders had no role in the study design, data collection and analysis, decision to publish or preparation of the manuscript.

\section{Disclosure}

The authors report no conflicts of interest in this work.

\section{References}

1. Bongaarts J. WHO, UNICEF, UNFPA, World Bank Group, and United Nations Population Division Trends in Maternal Mortality: 1990 to 2015 Geneva: World Health Organization, 2015. Population and Development Review. 2015;42:726-726.

2. Alkema L, Chou D, Hogan D, et al. Global, regional, and national levels and trends in maternal mortality between 1990 and 2015, with scenario-based projections to 2030: a systematic analysis by the UN Maternal Mortality Estimation Inter-Agency Group. Lancet. 2016; 387(10017):462-474

3. Say L, Chou D, Gemmill A, et al. Global causes of maternal death: a WHO systematic analysis. Lancet Glob Health. 2014;2(6):e323-e333.

4. Thaddeus S, Maine D. Too far to walk: maternal mortality in context Soc Sci Med. 1994;38(8):1091-1110.

5. JHPIEGO. Maternal and Neonatal Health Program. Birth Preparedness and Complication Readiness: A Matrix of Shared Responsibilities. Baltimore, USA: JHPIEGO; 2001. 
6. Tura G, Afework MF, Yalew AW. The effect of birth preparedness and complication readiness on skilled care use: a prospective follow-up study in Southwest Ethiopia. Reprod Health. 2014;11(1):1-10.

7. Soubeiga D, Gauvin L, Hatem MA, Johri M. Birth Preparedness and Complication Readiness (BPCR) interventions to reduce maternal and neonatal mortality in developing countries: systematic review and metaanalysis. BMC Pregnancy Childbirth. 2014;14(1):1-11.

8. Hailu M, Gebremariam A, Alemseged F, Deribe K. Birth preparedness and complication readiness among pregnant women in Southern Ethiopia. PLoS One. 2011;6(6):e21432.

9. Omari PK, Afrane YA, Ouma P. Birth preparedness and complication readiness among women attending antenatal care clinic in health facilities within Bureti Sub County of Kericho County, Kenya. American JMMS. 2016;6(4):123-128.

10. Rajesh P, Swetha R, Rajanna M, Krishna Iyengar MS. A study to assess the birth preparedness and complication readiness among antenatal women attending district hospital in Tumkur, Karnataka, India. IJCMPH. 2016;3(4):919-924.

11. JHPIEGO. Monitoring Birth Preparedness and Complication Readiness: Tools and Indicators for Maternal and Newborn Health. Maryland, USA: JHPIEGO; 2004.

12. Agarwal S, Sethi V, Srivastava K, Jha PK, Baqui AH. Birth preparedness and complication readiness among slum women in Indore city, India. J Health Popul Nutr. 2010;28(4):383-391.

13. IBM Corp. IBM SPSS Statistics for Windows, Version 22.0. Armonk, NY: IBM Corp; 2013.

14. Kamineni V, Murki AD, Kota VL. Birth preparedness and complication readiness in pregnant women attending urban tertiary care hospital. J Family Med Prim Care. 2017;6(2):297-300.

15. Mutreja S, Kumar A. Knowledge and practice of birth preparedness among tribal women in Sukma District of Chhattisgarh, India. IOSRJHSS. 2015;20(3):66-71.

16. Mandal T, Biswas R, Bhattacharyya S, Kumar D, Das DK. Birth preparedness and complication readiness among recently delivered women in a rural area of Darjeeling, West Bengal, India. Am Med Stud Res J. 2015;2(1):14-20.

17. Patil M, Vedpathak V, Aswar N, Deo D, Dahire P. Birth preparedness and complication readiness among primigravida women attending tertiary care hospital in a rural area. Int J Community Med Public Health. 2016;3(8):2297-2304.

18. Wurapa AR, Abudey S, Ankomah A, Ayaga AB. Birth preparedness and complication readiness among pregnant women in Hohoe Municipality of Ghana. IJNRHN. 2016;3(2):93-104.
19. Ibadin SH, Adam VY, Adeleye O, Okojie OH. Birth preparedness and complication readiness among pregnant women in a rural community in southern Nigeria. S Afr J Obstet Gynaecol. 2016;22(2):47-51.

20. Hailemariam A, Nahusenay H, Hana EG, Abebe A, Getaneh B. Assessment of magnitude and factors associated with birth preparedness and complication readiness among pregnant women attending antenatal care services at public health facilities in Debrebirhan Town, Amhara, Ethiopia, 2015. GJMR (E) Gynecol Obstet. 2016;16(2):38-44.

21. Musa A, Amano A. Determinants of birth preparedness and complication readiness among pregnant woman attending antenatal care at Dilchora Referral Hospital, Dire Dawa City, East Ethiopia. Gynecol Obstet. 2016;06(02):1-5.

22. Bintabara D, Mohamed MA, Mghamba J, Wasswa P, Mpembeni RNM. Birth preparedness and complication readiness among recently delivered women in chamwino district, central Tanzania: a cross sectional study. Reprod Health. 2015;12(1):1-8.

23. Solnes Miltenburg A, Roggeveen Y, Shields L, et al. Impact of birth preparedness and complication readiness interventions on birth with a skilled attendant: a systematic review. PLoS One. 2015;10(11):e0143382.

24. Perreira KM, Bailey PE, de Bocaletti E, Hurtado E, Recinos de Villagrán S, Matute J. Increasing awareness of danger signs in pregnancy through community- and clinic-based education in Guatemala. Matern Child Health J. 2002;6(1):19-28.

25. Mbalinda SN, Nakimuli A, Kakaire O, Osinde MO, Kakande N, Kaye DK. Does knowledge of danger signs of pregnancy predict birth preparedness? A critique of the evidence from women admitted with pregnancy complications. Health Res Policy Syst. 2014;12(1):1-7.

26. Zepre K, Kaba M. Birth preparedness and complication readiness among rural women of reproductive age in Abeshige district, Guraghe zone, SNNPR, Ethiopia. Int J Womens Health. 2017;9:11-21.

27. Henok A. Knowledge towards birth preparedness and complication readiness among mothers who attend antenatal care at Mizan-Aman General Hospital, South West Ethiopia. J Health Med Nurs. 2015;15:51-57.

28. Bitew Y, Awoke W, Chekol S. Birth preparedness and complication readiness practice and associated factors among pregnant women, Northwest Ethiopia. Int Sch Res Notices. 2016;2016:1-8.

29. Tilahun T, Sinaga M. Knowledge of obstetric danger signs and birth preparedness practices among pregnant women in rural communities of Eastern Ethiopia. Int J Nurs Midwifer. 2016;8(1):1-8.
International Journal of Women's Health

\section{Publish your work in this journal}

The International Journal of Women's Health is an international, peerreviewed open-access journal publishing original research, reports, editorials, reviews and commentaries on all aspects of women's healthcare including gynecology, obstetrics, and breast cancer. The manuscript management system is completely online and includes

\section{Dovepress}

a very quick and fair peer-review system, which is all easy to use Visit http://www.dovepress.com/testimonials.php to read real quotes from published authors. 